\title{
Otizmli Bireylerin Eğitiminde Video ile Model Olma Uygulamalarının Değerlendirilmesi: Bir Alanyazın Derlemesi ve Meta-Analiz Örneği
}

\author{
Necdet Karasu * \\ Gazi Üniversitesi
}

$\ddot{O}_{z}$

Otizmli bireylerin eğitimlerinde teknolojinin de gelişmesi ile beraber video ile model kullanımı konusunda ilerlemeler kaydedilmiş̧tir. Bu yöntemin etkililiğinin test edildiği tek denekli araştırma modellerine dayanan araştırmaların, niteliksel ve niteliksel özetlemeleri alanyazınını takip etmekte olan uygulamacı ve araştırmacılar için yardımcı olacaktır. Bu çalışmada otizmli bireylerle gerçekleştirilmiş, 2005 sonrası yayınlanmış, 24 adet tek denekli araştırma modeli kullanmış makale incelenmiştir. Ayrıca örtüşmeyen verilerin yüzdesi yöntemi ile etki büyüklüğ̈̈ hesaplamaları da yapılarak, niceliksel sonuçlar da elde edilmiştir. Toplamda 59 katılımcinın yer aldı̆̆ bu çalışmalarda iletişim, günlük yaşam becerileri, özbakım becerileri ve mesleki eğitim becerilerinin geliştirilmesi konularına odaklandıkları belirlenmişstir. Bu çalışmalar sonucunda otizmli bireylerin hedeflenen davranışlar üzerinde gelişme gösterdiklerine dair veriler elde edilmekle birlikte bazı sorular da ortaya çımış̧tır.

Anahtar Sözcükler: Meta-analiz, videoyla model olma, gözden geçirme

\begin{abstract}
Use of video modeling in education of autism is in increase in regard to the developments in technology. The quantitative and qualitative summaries of studies which based on single subject research methodology focused on the effectiveness of this method is important to the researchers and the teachers. This study reviewed 24 single subject design studies focused on students with autism and published after 2005. Also, effect-size calculations were completed by using percentage of nonoverlapping data method. Those selected studies included 59 participants and focused on communication skills, daily living skills, self-care skills and work skills. Even though the results have indicate to improvement on the selected behaviors, some questions have been also raised.
\end{abstract}

Key words: Meta-analysis, video modeling, review

Otizm spektrum bozukluğu (OSB) etkilediği bireyde sosyal, iletişimsel ve davranışsal sorunlara yol açan karmaşık bir nörolojik sorun olarak ortaya çıkmaktadır (Amerikan Psikiyatristler Birliği, 2000). OSB'den

\footnotetext{
*Yrd. Doç. Dr. Gazi Üniversitesi, Gazi Eğitim Fakültesi, Özel Eğitim Bölümü, Ankara, E-posta: necdetkarasu@gazi.edu.tr
} 
etkilenmiş bireylerin eğitimi için oluşturulan programlardan etkili sonuçlar elde edebilmek için eğitimde delile dayalı yöntemlerin (Evidence-based practices) kullanılması bir gereklilik halini almaktadır. Video ile model olmaya dayanan müdahalelerin, otizmli bireylerin eğitiminde delile dayalı bir yöntem olarak adlandırılabilmesi için alanyazının niceliksel ve niteliksel özetlemelerle bir araya getirilmesi uygun olacaktır.

19. yüzyılın son çeyreğinde tıp alanında geliştirilmeye başlanan delile dayalı yöntemlerin kaydedilmesi çabası, geçtiğimiz yıllarda özel eğitim alanında da kabul görür hale gelmiştir (Odom, Brantlinger, Gersten, Horner, Thompson ve Harris; 2005). Fakat delilde dayalı yöntemler kavramının ortak tanımının geliştirilmesi özel eğitim alanında zaman almıştır. Stoiber (2002) 'delile dayalı yöntemler' ve 'deneysel destekli terapiler' kavramlarının sıklıkla birbirlerinin yerine kullanıldığını tespit ederken, Lloyd (2001) delile dayalı yöntemler terimini kısaca araştırma sonuçlarının kullanımı olarak betimlemiştir. Scholesser (2003) bu tanımı eğitimsel ve klinik araştırmalardan gelen en iyi ve güncel delillerin kullanımı olarak genişletmiştir. Nelson ve Epstein (2002) ise delile dayalı yöntemlerin tanımını yaparken, elde edilen verilere dikkat çekmenin yanında, çalışmanın desen ve örnekleminin iyi oluşturulup oluşturulmadığı gibi ilişkili niteliklerin de önemini vurgulamışlardır.

Delile dayalı yöntemlerin ne olduğunun tanımı ancak 2005 yılında Amerikan Engelliler Konseyi (Council for Exceptional Children) Araştırma Birimi'nin (Research Division) bir araya getirdiği çalışma grubu tarafindan kabul edilen tanımla ortak bir ifadeye kavuşmuştur. Odom, Brantlinger, Gersten, Horner, Thompson ve Harris (2005) delile dayalı yöntemleri tanımlarken Erken Çocukluk Gelişimi Araştırma ve Eğitim Merkezi’nin (Research and Training Center on Early Childhood Development-CED) belirlediği daha işlevsel bir tanımlama olan "deneysel olarak yapılandııılmış ve çevresel değişkenlerin, özellikleri ve sonuçları hakkında ilişkileri açıklayan çalışmaların uygulayıcılar tarafından istenen sonuçları oluşturmak amacıyla doğrudan kullanılmasıdır" ifadesini kullanmışlardır. İstenen sonuçların oluşması için kullanılacak olan yöntemlerin tespiti ise farklı yaklaşımları da beraberinde getirmiştir. Bu Konsey tarafindan oluşturulan çalışma grupları niteliksel çalışmalar, tek denekli çalışmalar, korelasyon çalışmaları ve grup desenli çalışmalardan elde edilen bilgilerin ve bu araştırmalarda test edilen öğretim yöntemlerinin delile dayalı olarak kabul edilmesi için gerekli olan en alt düzey ölçütleri de belirlemişlerdir. Böylelikle etkililiği test edilen her öğretim yöntemi doğrudan delile dayalı olarak adlandırılmaktan çıkarılmış, bu yöntem hakkında belirli bir düzeyde "delil" toplanması hedeflenmiştir.

Alanyazında yakın zamana dek "bilimsel temelli yaklaşımlar" kavramı ile "delile dayalı yöntemler" kavramı birbirinin yerine kullanılabiliyor gibi görünse de aralarında bir ayrım bulunmaktadır. Bir müdahale yönteminin etkililiği hakkında bilimsel yollarla veri toplanarak bilgi oluşturulması doğrudan delile dayalı yöntem olarak adlandırılması için yetmemektedir. CEC tarafından belirlenen ölçütler yöntemlerin delile dayalı olarak adlandırılabilmesi için uygun görünmektedir.

Test edilen yöntemler hakkında bilgi bütünü oluşturmanın yolu eldeki bilgileri bir araya getirmek, yani sentezini oluşturmaktır. Böylelikle, elde edilen veriye dayanarak hangi yöntemlerin öncelikli olarak tercih edilip, kullanılması gerektiğini bize işaret edecek olan deliller analizlerle ortaya çıkacaktır. Bu nedenle, senteze dayalı özetleme yöntemlerinin kullanımı ile alanyazında toplanmakta olan araştırma sonuçlarının delile dayalı yöntem olarak adlandırılması bir zorunluluk olmuştur. Kavale (1984) alanyazından sentez oluştururken kullanılacak yöntemleri niteliksel ve niceliksel özetlemeler olarak ikiye ayırmıştır. Alanyazın derlemeleri, alanyazının niteliksel özetlemesinden sentez oluşturmak için kullanılan bir yöntem olarak tanıtılmaktadır. Meta-analiz ise çeşitli araştırma sonuçlarının niceliksel olarak özetlenmesi amacıyla geliştirilen bir yöntem olmuştur.

\section{Meta-analiz(meta analysis) ve Derleme (review) çalışmaları}

Derleme ve Meta-analiz çalışmaları özel eğitim alanında uzun zamandır yapılmaktadır. Fakat derleme çalışmaları, Kavale (1984)'nin de belirttiği gibi, çeşitli nedenlerle güvenirliği sorgulanan bir yaklaşım olarak değerlendirilebilirler. Kavale derleme çalışmalarının objektif olmaktan uzaklaşabileceğini savunmuştur. $\mathrm{Bu}$ kaygısına neden olarak da gerçekleştiren çalışmanın, araştırmacıların kişisel düşünce ve yaklaşımlarının çalışmaya nasıl yansıdığının kestirilememesi olarak ileri sürmüştür. Ayrıca, niteliksel özetlemeler özetlenen çalışmalar hakkında sadece genel çizgiler sağlamaktadır. Özetlemesi yapılan araştırmalarda kullanılan 
yöntemlerin delile dayalı yöntem olarak adlandırılmasında CEC tarafından belirlenen ölçütlerin karşılanıp karşılanmadığı hakkında fikir sağlamamaktadır. Niceliksel özetlemeler bu bakımdan niteliksel özetlemelerden farklılaşmaktadır.

Niceliksel özetlemeler olarak Kavale (1984)'ninde belirttiği gibi meta-analizler kendilerinden önceki derleme çalışmalarına göre sağladıkları daha üst düzey nesnellikle öne çıkmışlardır. Kavale (2001) özel eğitim alanının belli değişkenlerin varlığında ne tür müdahalelerden faydalanılabileceği hakkında sağlam veriler oluşturmayan bir alan olduğunu vurgulamaktadır. Ek olarak, gelişen alanyazından elde edilen bilginin bir araya getirilerek öğretmenlerin işlerini kolaylaştırmaktan uzak olduğunu da vurgulamıştır. Forness (2001) derleme çalışmalarının özel eğitim alanında delile dayalı yöntemler in ne olduğunu belirlemekte kesinlikle yeterli olmadığını belirtmiştir. Delile dayalı yöntemler hakkında karar vermek için çalışmaların "gücünün” dikkate alınması gerektiğini bu nedenle niceliksel özetleme yöntemi olarak meta-analizin etki-büyüklüğ̈̈ hesaplamaları sayesinde çok daha uygun bir yaklaşım olduğunun altını çizmiştir.

\section{Örtüşmeyen verilerin yüzdesi (ÖVY) yöntemi ile meta-analiz}

Meta-analiz araștırma sonuçlarının niceliksel olarak sentezlenmesi için önerilen bir yöntemdir. Bu özetlemenin gerçekleştirilebilmesi için niceliksel verilere ihtiyaç duyulmuştur. Bu nedenle etki büyüklüğü hesaplama yöntemleri geliştirilmiştir. Tek denekli çalışmalarda etki büyüklüğü hesaplaması bir problem olarak araştırmacıların karşısına çıkmıştır. Scruggs, Mastropieri ve Casto (1987) tek denekli çalışmalar için kullanılabilecek bir etki büyüklüğü hesaplama yöntemi geliştirerek adını örtüşmeyen verilerin yüzdesi (The Percentage of Non-Overlapping Data) olarak koymuşlardır. Bu yöntem en yaygın olarak kullanılmakta olan yöntemlerden biri haline gelmiştir. Adı geçen araştırmacılar geliştirdikleri bu yöntemle başlama ve müdahale düzeylerinin görsel karşılaştırılmasının niceliksel olarak ifade edilebilmesini hedeflemişlerdir. Aynı araştırmacıların yorumuna göre iki safha arasındaki örtüşmeyen veri noktalarının farkının yüzdesi sonuçların değerlendirilmesinde ciddi rol oynayabilir (Scruggs ve Mastropieri, 1997). Etki düzeyini hesaplamak için başlama düzeyindeki en yüksek veri noktası belirlendikten sonra o noktadan yatay eksene paralel olarak müdahale safhasının içine bir doğru çizilir. Bu doğrunun net olarak üst kısmında kalan verilerin sayısı sağaltım safhasında bulunan toplam veri sayısına bölünür. Bu sayı daha sonra 100 ile çarpılarak bir yüzde belirlenir (Scruggs ve diğerleri, 1987). Bu yüzde etki büyüklüğü olarak kabul edilmektedir. Belirlenen etki-büyüklüğü $\% 25$ ve altında ise etkisiz, \%50’ye kadar olan değerler orta etkili ve \%75 üzerindeki değerler etkili olarak tanitılmaktadır.

Bandura (1977) çocukların çok sayıda bilgi ve beceriyi etrafındakileri gözlemleyerek kazandığını belirtmiştir. Bunun yanında gözlemcinin gözlemlediği davranışları pekiştireç ihtiyacı olmadan gözlediklerini taklit ederek geliştirdiğini de belirtmiştir. Video ile model olmanın temelinde yatan bilgi Bandura'nın altını çizdiği bu bilgidir. Video ile model olma arzulanan davranışın video üzerinden hedef bireye izlettirilmesine dayanan bir müdahaledir (Bellini ve Akullian, 2007). Bu müdahalede birey bir görüntü izler ve ardından davranışı taklit eder. Video ile kendine model olma ise benzer biçimde gerçekleştirilmektedir. Tek farklılık bireyin kendisinin zaman içinde başarı ile gerçekleştirmiş olduğu bir performansının görüntüsünü izlemesine dayanmaktadır. Otizm ve diğer yaygın gelişimsel gerilikten etkilenmiş bireylerin eğitiminde daha sıklıkla kullanılmakta olan bir yöntem haline gelmiştir (Bellini ve Akullian, 2007). Fakat bu yöntem daha önce delilde dayalı yöntem olarak değil, ümit vaadeden yöntem olarak adlandırılmıştır (Karasu, 2008).

\section{Çalışmanın Amacı}

Ayres ve Langone (2005) otizmden etkilenmiş öğrencilerin becerilerini geliştirmeyi hedefleyen tek denekli çalışmalarda video ile model olma çalışmalarını derlemişlerdir. Ardından Bellini ve Akullian (2007)'ın gerçekleştirdikleri meta-analiz çalışması 2005 yılının sonuna kadar yayınlanmış çalışmaların niceliksel özetini çıkarmıştır. Bu çalışmanın amacı, video ile model olma tekniğinin otizmden etkilenmiş öğrencilerin becerilerini geliştirmeyi hedefleyen ve tek denekli araştırma modelleriyle gerçekleştirilen araştırmaların niteliksel ve niceliksel özetlenmesini yapmaktır. Bu çalışma bir derleme çalışması olarak Ayres ve Langone'nin çalışmasını 
ve aynı zamanda bir meta-analiz çalışması olarak Bellini ve Akullian'ın çalışmasını devam ettirmeyi hedeflemiş̧ir.

\section{Yöntem}

\section{Analize alınacak çalışmaların belirlenmesi}

Alanyazın incelemesinde yer alan çalışmaların belirlenmesi için öncelikle EBSCOHost, ERIC, PsychInfo ve internet arama motorlarından faydalanılmıştır. Belirlenen makaleler içindeki kaynaklar da incelenerek elektronik tarama esnasında belirlenemeyen çalışmalarda bu çalışmaya dahil edilmiştir. Elektronik tarama esnasında otizm, otizm bozukluğu, rett sendromu, asperger, yaygın gelişimsel bozukluk, video ile model olma, video ile kendine model olma ve tek denekli çalışmalar anahtar kelimeleri kullanılmıştır.

\section{Meta-analiz için kabul ölçütleri}

Tarama esnasında belirlenen 50 den fazla makale aşağıda belirtilen ölçütler dikkate alınarak detaylı biçimde incelenmiştir. Bu ölçütler, a) katılımcıların aldığı tanı, b) çalışmanın araştırma modeli, c) basım dili, d) hakemli dergide basılmış olması ve e) video ile model olma uygulamalarından birinin tercih edilmiş olması şeklindedir.

Belirlenen ölçütleri karşılayan çalışmalar, yazarları, basım tarihleri, bağımlı ve bağımsız değişkenleri, içerdikleri katılımcı sayısı, katılımcıların tanıları, uyguladıkları tek denekli modeli, yaş grupları, cinsiyetleri ve sonuçlarına göre sınıflandırılmışlardır.

\section{Kodlamacılar Arası Güvenilirlik}

Belirlenen çalışmaların \%25'i diğer bir araştırmacı tarafından ölçütler dahilinde detaylı biçimde incelenmiştir. Bu sayede çalışmalardan elde edilen verilerin doğru biçimde niteliksel özetlemeye dahil edilip edilmediğini kontrol edilmiştir.

\section{Bulgular}

Belirlenen ölçütlere göre otizmli bireylerle video ile model olmanın etkililiğini inceleyen çalışmalardan 2005 yılı sonrasında gerçekleştirilen 24 çalışma tespit edilmiştir. Bu çalışmaların bağımlı, bağımsız değişkenleri, katılımcı özellikleri ve diğer özellikleri aşağıda özetlenmiştir.

\section{Kodlamacılar Arası Güvenirlik}

Çalışmanın yazarı ve diğer kodlayıcı arasındaki güvenirlik \%100 oranında tespit edilmiştir.

\section{ÖVY Analizi Sonuçları}

İçerilen çalışmalardan elde edilen ÖVY değerleri \%0 ile \% 100 arasında değişmiştir. Toplam 24 çalışmadan elde edilen yüzdelik ortalama \% 69 olarak belirlenmiştir. Çalışmalar için elde edilen ortalama değerler ve genel ortalama tablo 1 . de listelenmiştir.

\section{Araştırmaların Bağımlı Değişkenleri}

Meta-analize dahil edilen araştırmalar çeşitli davranışlarda gelişme sağlamayı hedeflemişlerdir. Bu hedefler, sosyal becerilerin, iletişim becerilerinin, oyun becerilerinin, özbakım becerilerinin, iş becerilerinin ve geçiş becerilerinin geliştirilmesi olarak sınıflanabilmektedir. Araştırmacıların otizmden etkilenmiş bireylerle video ile model olma müdahale yöntemini en çok iletişim becerileri ve sosyal becerilerin geliștirilmesinde kullandıkları dikkati çekmektedir. Otizmli bireylerin sosyal becerilerde ve iletişim davranışlarında akranlarından anlamlı biçimde farklılaştıkları değerlendirilirse araştırmaların bağımlı değişkeni olarak bu konularda odaklanmaları şaşırtıcı değildir. Çalışmaların büyük kısmı video ile model olma yöntemini hedeflenen davranışların geliştirilmesinde etkili olarak değerlendirirken 8 çalışmada (toplam çalışma sayısının 1/3'ü) rapor edilen sonuçların, rapordaki sonuç yorumlamasıyla uyumlu olmadığı belirlenmiştir (Banda, Copple, Koul, 
Sancibrian ve Bogschutz, 2010; Buggey, Hoomes, Sherberger ve Williams, 2009; Deitchman, Reeve, Reeve, Progar, 2010; Keen, Brannigan ve Cuskelly, 2007; Maione ve Mirenda, 2006; Mechling, Gast ve Cronin, 2006; Paterson ve Arco, 2007; Sansosti ve Powell-Smith, 2008). Araştırmacılar ya etkili sonuçlar elde edildiğini ya da etkili ama bazı sınırlılıklar da var tarzında yorumlamalara gitmişlerdir. Bahsi geçen 8 çalışmanın grafikleri ile ilgili daha geniş bir analize yer verilmiştir.

Sınırlı gelişme olduğu rapor edilen sekiz çalışmadan yedisinde sosyal ve iletişim becerileri ile oyun becerileri çalışılırken bir tanesi tuvalet eğitimi üzerinedir. Bu çalışmaların rapor edilen figürleri görsel analizle incelendiğinde düzey ve eğim bakımından ilginç sonuçlara ulaşılmaktadır. Banda, Copple, Koul, Sancibrian ve Bogschutz (2010) tarafından gerçekleştirilen çalışmada iki katılımcı yer almıştır ve ikinci katılımcının müdahale aşamasında uygun bir analiz gerçekleştirmek için yeterli olmayan gözlem sayısı olduğu görülmüştür. Diğer katılımcının gelişimini gösteren figürde ise düzey olarak hafif bir yükselme varken eğim olarak inen bir eğim tespit edilmiştir. Çalışmanın amacının davranış arttırma olduğu göz önünde bulundurulursa elde edilen veriler etkililik göstermekten uzaktır. Banda ve diğerleri tarafından gerçekleştirilen çalışmanın ÖVY değeri de şüpheli değerler arasında kalmaktadır. Buggey, Hoomes, Sherberger ve Williams (2009) tarafından gerçekleştirilen çalışmada ise 4 katılımcı bulunmaktadır. Sadece 1. katılımcıya ilişkin verilerde düzey diğerlerine göre yükselmiştir, katılımcı 3 ve 4'te düzey çok sınırlı olarak değişmiştir. Eğim olarak ise 4 katılımcıya ait verilerin eğiminin neredeyse hiç yükseliş veya iniş göstermeden aynen devam ettiği belirlenmiştir. Çalışmanın ÖVY değerleri ise etkisiz uygulamalar sınırı içine düşmektedir. Deitchman, Reeve, Reeve ve Progar'ın (2010) çalışmasında 3 katılımeı yer alırken ilk iki katılımcı için düzey artışı çok belirginken 3. de aynı biçimde bir düzey artışı olmamıştır. Fakat ilk iki katılımcının gözlemler ilerledikçe eğimin iniş seyrine girdiği belirlenmiştir. Buna rağmen ÖVY değeri \% 91 olarak hesaplanmıştır. Keen, Brannigan ve Cuskelly (2007) çalışması tartışılan çalışmalardan özbakım becerisi içeren tek çalışmadır ve 3 katılımcıyı yer alımştır. Katılımcıların grafiklerinin müdahale aşamaları incelendiğinde düzeylerin çok sınırlı olarak artarken, eğimlerin ise sadece bir düz çizgi olarak gittiği belirlenmiştir. Bu durum aynen ÖVY sonuçlarında da tespit edilmiş, değer ancak \% 33 belirlenmiştir. Maione ve Mirenda (2006) çalışmasında ise 3 katılımcının ikisinde toplam değerler yükselme gösterirken iki katılımcı için eğim düz, bir katılımcı için ise eğim iniş seyrine girmiştir. ÖVY sonuçları da benzer bir durum yansıtmıştır, ancak \% 51'lik bir değer elde edilmiştir. Mechling, Gast ve Cronin (2006) çalışmasında ise iki katılımcı dönüşümlü modelle kendi içlerinde kontrol edilmişlerdir. Katılımcıların birinde başlangıç aşamasına dönüldüğünde ilk başlangıç aşamasından hafifçe farklılaşırken, iki katılımcının B1-B2 evrelerinin çok benzer düzeylere ulaştığı tespit edilmiştir. Fakat çalışmalarda eğimlerin A1-A2 evrelerinden neredeyse hiç farklılaşmadığ 1 da görülmektedir. Bu çalışma için elde edilen \% 67 ise görsel analizdeki durumla uyumlu olduğu düşünülmektedir. Paterson ve Arco (2007)'nun çalışmasında ise özetlenen diğer bazı çalışmalara benzer olarak 3 katılımcınında da düzey olarak farklılaşma göstermekle beraber başlama düzeyleri ile müdahale evreleri karşılaştırıldığında eğim olarak belirgin bir değişim göstermemekte, eğim düz olarak devam etmektedir. ÖVY'de ancak \% 43'lük bir değer ortaya koyarak görsel analizi destekleyen bir sonuç ortaya çıkarmıştır. Sansosti ve Powell-Smith (2008) çalışması ise elde edilen verileri ciddi biçimde tartışmaya açabilecek figürler içermektedir. Çalışmanın 3 katılımcısının her üçünde de düzey değişikliği görülmektedir. Fakat 2 katılımcının düzeyleri 3 ve 4. gözlemlerden sonra belirgin biçimde düşüşe geçerek başlama düzeyindeki bazı veri düzeylerinin altına inerken eğim çok belirgin biçimde inişe geçmektedir. Çalışma diğer bir değişken olarak video model olmayı ipucu sistemleriyle birleştirerek kullandığında ise tekrar artış tespit edilmiştir. Her ne kadar bu çalışma figürleri tartışmaya açık da olsa ÖVY değerleri etkili sonuca işaret etmektedir. Video ile model olma hedeflenen sosyal iletişim becerilerini geliştirmede ipucu sistemleri devreye girmeden başarılı sonuçlar üretememiştir fakat araştırmacılar tarafından etkili olarak değerlendirilmiştir. Sonuç olarak araştırmacılar tarafından video ile model olmaya dayana yöntemlerin otizmli bireylerin eğitiminde delile dayalı bir yöntem olarak değerlendirilmesi uygun olacak gibi görünmektedir.

\section{Araştırmaların Bağımsız Değişkenleri}

Çalışmalarda video ile model olma çoğunluğu oluşturmuştur. Bunu izleyen bağımsız değişkenin video ile kendine model olma olduğu tespit edilmiştir. Sadece bir çalışmada video dönüt bağımsız değişken olarak değerlendirilirken iki çalışmada video ile model olma sosyal öykü kullanımı ile birleştirilmiştir. 


\section{Çalışmaların Katılımcı Özellikleri Hakkında}

Çalışmalarda yer alan katılımcıların özellikleri incelendiğinde toplam 59 katılımcının 56' sının OSB tanısı almış bireyler oldukları belirlemiştir. İki katılımcı yaygın gelişimsel bozukluk tanısı ile sınıflanırken sadece bir katılımcı asperger tanısı taşımaktadır. Yaş grubu olarak incelediğimizde katılımcıların en gencinin 2 yaşında, en yaşlısının 43 yaşında olduğu tespit edilmiştir. En sık rastlanan yaş 4 olarak tespit edilirken katılımcıların 30 tanesinin 0-6 yaş aralığında olduğu belirlenmiştir. 24 katılımcının 7-18 yaş aralığında olduğu geriye kalan 5 katılımcının da 19 yaş ve üzerinde olduğu belirlenmiştir. Katılımcıların cinsiyet dağılımı ise 47 erkek 12 kadın katılımcı biçiminde olmuştur. Otizm tanısının yaklaşık olarak 4:1 oranında erkeklerde daha sık görüldüğü düşünülürse bu dağılım tamamen beklentileri karşılayacaktır.

Tablo 1.

Çalışmaların Özeti

\begin{tabular}{|c|c|c|c|c|c|c|c|c|c|c|}
\hline Yazar & Tarih & $\begin{array}{l}\text { Bağımlı } \\
\text { Değişken }\end{array}$ & $\begin{array}{l}\text { Bağımsız } \\
\text { Değışken }\end{array}$ & $\mathrm{N}$ & $\begin{array}{l}\text { Araştırma } \\
\text { Yöntemi }\end{array}$ & Engel & Yaş grubu & cinsiyet & $\begin{array}{l}\text { Rapor Edilen } \\
\text { Sonuç }\end{array}$ & $\begin{array}{l}\ddot{V Y} \\
(\%)\end{array}$ \\
\hline $\begin{array}{l}\text { Allen, } \\
\text { Wallace, } \\
\text { Renes, } \\
\text { Bowen \& } \\
\text { Burke }\end{array}$ & 2010 & $\begin{array}{l}\text { İş becerileri ( } \\
\text { el sallama, el } \\
\text { sikma, ve } \\
\text { benzeri) }\end{array}$ & $\begin{array}{l}\text { Video ile model } \\
\text { olma }\end{array}$ & 4 & $\begin{array}{l}\text { Denekler } \\
\text { arası çoklu } \\
\text { yoklama }\end{array}$ & OSD & $\begin{array}{l}16,17,18, \\
25\end{array}$ & E,E,E,E & $\begin{array}{l}\text { Katılımcılar } \\
\text { becerileri } \\
\text { kazanmışlardır }\end{array}$ & 5 \\
\hline $\begin{array}{l}\text { Banda, } \\
\text { Copple, } \\
\text { Koul, } \\
\text { Sancibrian, } \\
\text { \& Bogschutz }\end{array}$ & 2010 & $\begin{array}{l}\text { Tercih edilen } \\
\text { nesneyi isteme }\end{array}$ & $\begin{array}{l}\text { Video ile model } \\
\text { olma }\end{array}$ & 2 & $\begin{array}{l}\text { Denekler } \\
\text { arası çoklu } \\
\text { yoklama }\end{array}$ & OSD & 21,21 & $\mathrm{E}, \mathrm{E}$ & $\begin{array}{l}\text { Bazı öncül veriler } \\
\text { elde edilmiştir }\end{array}$ & 66 \\
\hline $\begin{array}{l}\text { Bellini, } \\
\text { Akullian, \& } \\
\text { Hopf }\end{array}$ & 2007 & $\begin{array}{l}\text { Sosyal ilişskide } \\
\text { bulunma }\end{array}$ & $\begin{array}{l}\text { Video ile } \\
\text { kendine model } \\
\text { olma }\end{array}$ & 2 & $\begin{array}{l}\text { Denekler } \\
\text { arası çoklu } \\
\text { yoklama }\end{array}$ & OSD & 4,5 & $\mathrm{E}, \mathrm{E}$ & Etkili bulunmuştur & 80 \\
\hline $\begin{array}{l}\text { Blum- } \\
\text { Dimaya, } \\
\text { Reeve, } \\
\text { Reeve, } \\
\text { \&Hoch }\end{array}$ & 2010 & $\begin{array}{l}\text { Boş zaman } \\
\text { değerlendirme } \\
\text { (bilgisayar } \\
\text { oyunları) }\end{array}$ & $\begin{array}{l}\text { Oyun içine } \\
\text { gömülmüş } \\
\text { eşzamanlı video } \\
\text { modellerin } \\
\text { kullanımı }\end{array}$ & 4 & $\begin{array}{l}\text { Denekler } \\
\text { arası çoklu } \\
\text { başlama }\end{array}$ & OSD & $11,111,12,9$ & $\mathrm{E}, \mathrm{E}, \mathrm{E}, \mathrm{G}$ & Etkili bulunmuştur & 88 \\
\hline $\begin{array}{l}\text { Boudreau \& } \\
\text { D'Entremont }\end{array}$ & 2010 & $\begin{array}{l}\text { Oyun } \\
\text { becerileri }\end{array}$ & $\begin{array}{l}\text { Video ile model } \\
\text { olma }\end{array}$ & 2 & $\begin{array}{l}\text { Denekler } \\
\text { arası çoklu } \\
\text { yoklama }\end{array}$ & $\begin{array}{l}\text { YGB, } \\
\text { YGB }\end{array}$ & 2,2 & $\mathrm{E}, \mathrm{E}$ & Etkili bulunmuştur & 58 \\
\hline $\begin{array}{l}\text { Buggey, } \\
\text { Hoomes, } \\
\text { Sherberger, } \\
\text { \& Williams }\end{array}$ & 2009 & $\begin{array}{l}\text { Sosyal ilişski } \\
\text { başlatma }\end{array}$ & $\begin{array}{l}\text { Video ile model } \\
\text { olma }\end{array}$ & 4 & $\begin{array}{l}\text { Denekler } \\
\text { arası çoklu } \\
\text { yoklama }\end{array}$ & OSD & $4,4,3,4$ & K,E,E,K & $\begin{array}{l}\text { Başarılı } \\
\text { bulunmuştur ama } \\
\text { bir denekteki } \\
\text { gelişme yetersiz } \\
\text { bulunmuştur }\end{array}$ & 48 \\
\hline $\begin{array}{l}\text { Charlop, } \\
\text { Dennis, } \\
\text { Carpenter, \& } \\
\text { Greenberg }\end{array}$ & 2010 & $\begin{array}{l}\text { Sosyal } \\
\text { etkileşim } \\
\text { esnasinda } \\
\text { sözel } \\
\text { yorumlarda } \\
\text { bulunma, } \\
\text { tonlama, jest } \\
\text { ve mimikler }\end{array}$ & $\begin{array}{l}\text { Video ile model } \\
\text { olma }\end{array}$ & 3 & $\begin{array}{l}\text { Denekler } \\
\text { arası çoklu } \\
\text { yoklama }\end{array}$ & OSD & $11,8,7$ & $\mathrm{E}, \mathrm{E}, \mathrm{E}$ & $\begin{array}{l}\text { Ölçüt } \\
\text { karşılanmıştır }\end{array}$ & 88 \\
\hline $\begin{array}{l}\text { Cihak, } \\
\text { Fahrenkrog, } \\
\text { Ayres, \& } \\
\text { Smith }\end{array}$ & 2010 & $\begin{array}{l}\text { Geçiş } \\
\text { becerileri }\end{array}$ & $\begin{array}{l}\text { Video ile model } \\
\text { olma }\end{array}$ & 4 & $\mathrm{ABAB}$ & OSD & $6,7,7,8$ & $\mathrm{E}, \mathrm{E}, \mathrm{K}, \mathrm{E}$ & Etkili bulunmuştur & 92 \\
\hline $\begin{array}{l}\text { Deitchman, } \\
\text { Reeve, } \\
\text { Reeve, } \\
\text { Progar }\end{array}$ & 2010 & $\begin{array}{l}\text { Sosyal ilişki } \\
\text { başlatma }\end{array}$ & Video dönüt & 3 & $\begin{array}{l}\text { Denekler } \\
\text { arası çoklu } \\
\text { başlama }\end{array}$ & OSD & $6,5,7$ & $\mathrm{E} ; \mathrm{E}, \mathrm{E}$ & Etkili bulunmuştur & 91 \\
\hline
\end{tabular}




\begin{tabular}{|c|c|c|c|c|c|c|c|c|c|c|}
\hline $\begin{array}{l}\text { Hine \& } \\
\text { Wolery }\end{array}$ & 2006 & $\begin{array}{l}\text { Oyun } \\
\text { becerileri }\end{array}$ & $\begin{array}{l}\text { Point-of-view } \\
\text { Video ile model } \\
\text { olma }\end{array}$ & 2 & $\begin{array}{l}\text { Davranışlar } \\
\text { arası çoklu } \\
\text { yoklama, } \\
\text { Denekler } \\
\text { arası çoklu } \\
\text { başlama }\end{array}$ & OSD & 30,43 & $\mathrm{~K}, \mathrm{~K}$ & Etkili bulunmuştur & 60 \\
\hline $\begin{array}{l}\text { Keen, } \\
\text { Brannigan, \& } \\
\text { Cuskelly }\end{array}$ & 2007 & $\begin{array}{l}\text { Tuvalet } \\
\text { eğitimi }\end{array}$ & $\begin{array}{l}\text { Video ile model } \\
\text { olma }\end{array}$ & 5 & $\begin{array}{l}\text { Gruplar } \\
\text { arası çoklu } \\
\text { yoklama }\end{array}$ & OSD & $4,4,4,4,6$ & E,E,E,E,E, & $\begin{array}{l}\text { Bir dereceye kadar } \\
\text { etkili olacağ } \\
\text { değerlendirilmiștir }\end{array}$ & 33 \\
\hline $\begin{array}{l}\text { Kleeberger, } \\
\text { \& Mirenda }\end{array}$ & 2010 & $\begin{array}{l}\text { Taklit } \\
\text { becerileri }\end{array}$ & $\begin{array}{l}\text { Video ile model } \\
\text { olma }\end{array}$ & 1 & $\begin{array}{l}\text { Davranışlar } \\
\text { arası çoklu } \\
\text { yoklama }\end{array}$ & OSD & 4 & $\mathrm{E}$ & $\begin{array}{l}\text { Motor hareketlerin } \\
\text { geliştirilmesinde } \\
\text { yetişkinin video ile } \\
\text { model olması etkili } \\
\text { bulunmamıştır }\end{array}$ & 0 \\
\hline $\begin{array}{l}\text { Macdonald, } \\
\text { Sacramone, } \\
\text { Mansfied, } \\
\text { Wiltz, } \\
\text { Ahearn }\end{array}$ & 2009 & Hayali oyun & $\begin{array}{l}\text { Video ile model } \\
\text { olma }\end{array}$ & 2 & $\begin{array}{l}\text { Ortamlar } \\
\text { arası çoklu } \\
\text { yoklama }\end{array}$ & OSD & 7,5 & $\mathrm{E}, \mathrm{E}$ & $\begin{array}{l}\text { Katılımcılar } \\
\text { becerileri } \\
\text { kazanmıştır }\end{array}$ & 95 \\
\hline $\begin{array}{l}\text { Maione, \& } \\
\text { Mirenda }\end{array}$ & 2006 & Sosyal ifadeler & $\begin{array}{l}\text { Video ile model } \\
\text { olma ile video } \\
\text { dönüt }\end{array}$ & 1 & $\begin{array}{l}\text { Davranışlar } \\
\text { arası çoklu } \\
\text { yoklama }\end{array}$ & OSD & 5 & $\mathrm{E}$ & $\begin{array}{l}\text { Sosyal dil } \\
\text { gelissiminde etkili } \\
\text { bulunmuştur }\end{array}$ & 51 \\
\hline $\begin{array}{l}\text { Mechling, } \\
\text { Gast, \& } \\
\text { Cronin }\end{array}$ & 2006 & $\begin{array}{l}\text { Tercih edilen } \\
\text { nesneleri } \\
\text { sunma }\end{array}$ & $\begin{array}{l}\text { Video ile model } \\
\text { olma }\end{array}$ & 2 & $\mathrm{ABAB}$ & OSD & 13,14 & $\mathrm{E}, \mathrm{E}$ & $\begin{array}{l}\text { Davranışlarda } \\
\text { düşüş } \\
\text { gerçekleşmiştir }\end{array}$ & 67 \\
\hline $\begin{array}{l}\text { Murzynski \& } \\
\text { Bourret }\end{array}$ & 2007 & $\begin{array}{l}\text { Tepki zinciri } \\
\text { kurma }\end{array}$ & $\begin{array}{l}\text { Video ile model } \\
\text { olma ve ipucu } \\
\text { sistemleri }\end{array}$ & 2 & $\begin{array}{l}\text { Paralel } \\
\text { uygulamalar } \\
\text { modeli }\end{array}$ & OSD & 8,9 & $\mathrm{E}$ & Etkili bulunmuştur & 98 \\
\hline $\begin{array}{l}\text { Nikopoulos, } \\
\text { Canavan, \& } \\
\text { Nikopolou- } \\
\text { Smyrni }\end{array}$ & 2009 & $\begin{array}{l}\text { Oyuncak } \\
\text { temizleme }\end{array}$ & $\begin{array}{l}\text { Video ile model } \\
\text { olma }\end{array}$ & 3 & $\begin{array}{l}\text { Denekler } \\
\text { arası çoklu } \\
\text { yoklama }\end{array}$ & OSD & $7,8,9$ & $\mathrm{E}, \mathrm{K}, \mathrm{E}$ & Etkili bulunmuştur & 90 \\
\hline $\begin{array}{l}\text { Palechka \& } \\
\text { MacDonald }\end{array}$ & 2010 & $\begin{array}{l}\text { Oyun } \\
\text { becerileri } \\
\text { kazanma }\end{array}$ & $\begin{array}{l}\text { Ticari ve } \\
\text { kişiselleştirilmiş } \\
\text { video modeller }\end{array}$ & 3 & $\begin{array}{l}\text { Çoklu } \\
\text { element } \\
\text { modeli }\end{array}$ & OSD & $5,5,4$ & E,E, K & $\begin{array}{l}\text { Katılımcılara gore } \\
\text { farklılaşmakla } \\
\text { birlikte etkili } \\
\text { bulunmuștur }\end{array}$ & 94 \\
\hline $\begin{array}{l}\text { Paterson } \\
\text { \&Arco }\end{array}$ & 2007 & $\begin{array}{l}\text { Oyuncakla } \\
\text { Oynama }\end{array}$ & $\begin{array}{l}\text { Video ile model } \\
\text { olma }\end{array}$ & 2 & $\begin{array}{l}\text { Çoklu } \\
\text { başlama }\end{array}$ & OSD & 7,6 & $\mathrm{E}, \mathrm{E}$ & Etkili bulunmuştur & 43 \\
\hline $\begin{array}{l}\text { Rosenberg, } \\
\text { Schwartz, \& } \\
\text { Davis }\end{array}$ & 2010 & El yıkama & $\begin{array}{l}\text { Ticari videolar } \\
\text { ile model }\end{array}$ & 3 & $\begin{array}{l}\text { Eşzamanlı } \\
\text { denekler } \\
\text { arası çoklu } \\
\text { başlama }\end{array}$ & OSD & $5,4,3$ & E,E,E & $\begin{array}{l}3 \text { katılımcidan } 2 \\
\text { sinde öğrenme } \\
\text { gerçekleşmiştir }\end{array}$ & 62 \\
\hline $\begin{array}{l}\text { Sancho, } \\
\text { Sidener, } \\
\text { Reeve, \& } \\
\text { Sidener }\end{array}$ & 2010 & $\begin{array}{l}\text { Oyun } \\
\text { becerileri }\end{array}$ & $\begin{array}{l}\text { Video ile model } \\
\text { olma }\end{array}$ & 2 & $\begin{array}{l}\text { Denekler } \\
\text { arası çoklu } \\
\text { başlama }+ \\
\text { dönüşümlü } \\
\text { uygulamalar } \\
\text { modeli }\end{array}$ & OSD & 5,5 & $\mathrm{E}, \mathrm{E}$ & Etkili bulunmuştur & 97 \\
\hline $\begin{array}{l}\text { Sansosti \& } \\
\text { Powell-smith }\end{array}$ & 2008 & $\begin{array}{l}\text { Sosyal iletişim } \\
\text { becerileri }\end{array}$ & $\begin{array}{l}\text { Video modeller } \\
\text { ve bilgisayar } \\
\text { destekli sosyal } \\
\text { hikaye sunumu }\end{array}$ & 3 & $\begin{array}{l}\text { Denekler } \\
\text { arası çoklu } \\
\text { yoklama }\end{array}$ & OSD & $6,9,8$ & E,E,E & Etkili bulunmuştur & 72 \\
\hline Scattone & 2008 & $\begin{array}{l}\text { Karşılıklı } \\
\text { konuşma } \\
\text { becerileri }\end{array}$ & $\begin{array}{l}\text { Sosyal hikayeler } \\
\text { ve video ile } \\
\text { model olma }\end{array}$ & 1 & $\begin{array}{l}\text { Davranışlar } \\
\text { arası çoklu } \\
\text { yoklama }\end{array}$ & Asperger & 9 & $\mathrm{E}$ & $\begin{array}{l}3 \text { hedef } \\
\text { davranıştan } \\
\text { ikisinde ilerleme } \\
\text { görülmüştür }\end{array}$ & 77 \\
\hline \multirow[t]{2}{*}{$\begin{array}{l}\text { Tetreault, } \\
\text { \&Lerman }\end{array}$} & 2010 & $\begin{array}{l}\text { Sosyal } \\
\text { beceriler }\end{array}$ & $\begin{array}{l}\text { Point-of-view } \\
\text { Video ile model } \\
\text { olma }\end{array}$ & 3 & $\begin{array}{l}\text { Davranışlar } \\
\text { arası çoklu } \\
\text { yoklama }\end{array}$ & OSD & $5,8,4$ & E,E,K & $\begin{array}{l}3 \text { katılımcıdan } 2 \text { si } \\
\text { gelişirken } 3 \text {. } \\
\text { Katılımcı için } \\
\text { ipuçları } \\
\text { gerekmiştir }\end{array}$ & 47 \\
\hline & & & & & & & & & Ortalama ÖVY & 69 \\
\hline
\end{tabular}




\section{Çalışmaların Araştırma Modelleri}

$\mathrm{Bu}$ gözden geçirme çalışmasında makale seçim ölçütlerinden bir tanesi çalışmaların tek denekli araştırmaların deneysel modellerinden en az birini uygulamış olmasıdır. Üst analize dahil edilen tüm çalışmalar tek denekli araştırma modellerinden örnekler sergilemişlerdir. Bu modellerden en sık tercih edileni çoklu başlama düzeyi modelleri iken, izleyen tercih çoklu yoklama modelleri olmuştur. Ele alınan bağımlı değişkenler dikkate alındığında ve çok az sayıda farklı bağımsız değişkenleri karşılaştırma çalışması olduğundan çoklu başlama ya da yoklama modellerinin tercih edilmesi çok anlaşılırdır.

\section{Tartışma}

$\mathrm{Bu}$ çalışma sonunda elde edilen veriler video ile model olma yaklaşımının otizmli bireylerin eğitiminde kullanılabilecek delile dayalı yöntemlerden olarak sayılabilmesi için gerekli ipuçlarını vermektedir. Bellini ve Akullian (2007) tamamladıkları çalışmada ÖVY hesaplamalarını gerçekleştirirken inceledikleri çalışmaların normal müdahale sonuçları, genelleme ve süreklilik verileri için ayrı ayrı hesaplamalar gerçekleştirmişlerdir. $\mathrm{Bu}$ çalışma sadece incelenen çalışmaların müdahale sonrası için hesaplamaları gerçekleştirmiştir. Her ne kadar araştırmacılar net bir ortalama vermemiş olsalar dahi elde edilen verilerin bu çalışmada elde edilene çok yakın olduğu görülebilmektedir. Araştırmacılar video ile model olmanın delile dayalı yöntem olarak adlandırılabileceği yönünde görüş bildirmişlerdir. Benzer biçimde bu meta-analiz çalışması da aynı yargıya varmıştır. İki çalışma bu bakımdan oldukça paralel biçimde sonuçlandırılmıştır.

Delile dayalı yöntem olarak adlandırabileceğimiz video ile model olma yönteminin araştırmacılar tarafindan da daha çok test edilen bir yöntem olduğunu söylemek bu çalışma sonunda mümkün olmuştur. Ayres ve Langone (2005)'nin, 1989 ve 2005 yılları arasını kapsayarak tamamladıkları derleme çalışmasında sadece 15 çalışma yer almışken bu sayı 2006-2011 yılları arasında 24 olarak belirlenmiştir. Her ikisi de altışar yıllık aralıkları içerdikleri halde iki çalışma arasında içerilen çalışma sayısında artış olmuştur.

Video ile model olmanın otizmli öğrencilerin davranışları üzerindeki etkilerinin incelendiği çalışmaları özetleyen bu çalışmadan sonra bir konu tartışmaya açık hale gelmiştir. Scruggs ve Mastropieri (1997) ÖVY hesaplamaları ile elde edilen çalışmaların sonuçlarının yorumlanması konusunda dikkatli olunması gerektiğini vurgularken, \% 90 ve üzerini çok etkili, 70-90 aralı̆̆ını etkili, 50-70 aralığını şüpheli ve 50 den aşağısını ise etkisiz olarak belirtmişlerdir. Bu çalışmada incelenen çalışmaların ortalamaları temel alındığında ÖVY ile elde edilen verilerin çok kritik bir noktada durduğu düşünülebilir. \% 69-ile 70 arasındaki fark tanımlanabilir bir fark olmadığı için video ile model olmaya dayalı yöntemlerin şüpheli yöntem mi yoksa etkili bir yöntem mi olduğunu ileri sürmek çok kolay olmayacaktır. Scruggs ve Mastropieri'nin de belirttiği gibi elde edilen ÖVY değerleri çok dikkatli ele alınmalıdır. Ama burada müdahale yönteminin genel etkisi, rapor edilen sosyal geçerliliği ve kullanım kolaylığı gibi konular değerlendirildiğinde video ile model olma alanda kullanmak için uygun bir yöntem olarak ortaya çıkmaktadır.

Makalelerin niteliksel özetlemesinde (Tablo 1.) görüldüğü gibi araştırmacı yazarlar çalışmalarının sonuçlarını sıklıkla etkili olarak yansıtmışlardır. Fakat hem niteliksel özetleme, hem de görsel analize dayalı etki-büyüklüğü hesaplama yöntemi çalışmaların iddia edilen etkililiğini sorgulanır hale getirmektedir. Odom, Collet-Klienberger, Rogers ve Hatton (2010) yaptıkları incelemede video ile model olmayı otizmli çocukların davranış, iletişim, oyun, sosyal ve geçiş becerilerinin geliştirilmesinde kullanılabilecek delile dayalı yöntem olarak adlandırırken verilerin aynı yöntemi akademik beceriler için delile dayalı yöntem olarak işaret etmediğini göstermişlerdir. Bu derleme ve meta-analiz çalışmasında da içerilen araştırmaların hiçbiri akademik beceri geliştirmeyi hedeflemediği görülmüştür.

\section{Öneriler}

Video ile model olmanın etkililiği hakkında elde edilen verilerin bu yöntemin daha farklı durum, ortam ve hedefler için test edilmesi gerektiği de görülmektedir. Öncelikle akademik beceriler için etkililiğinin test edilmesi değerlendirilebilir fakat akademik beceriler üzerinde etkili olmaması beklenebilecek bir durumdur. 
Bunun dışında, ağırlıklı olarak klinik çalışmalar biçiminde devam eden video ile model olma çalışmalarında öğretmen tarafından kullanabilirliğinin de incelenmesinde fayda olacaktır. Sadece sosyal geçerlik verisi olarak öğretmen görüşü alınması yetmemektedir. Video hazırlama ve kullanımı aşamaları öğretmenler tarafından nasıl gerçekleştirilebildiği veya gerçekleştirilebileceği çalışmalarda tamamlanmalıdır.

Test edilme sayısı gittikçe artan video ile model olma yönteminin çeşitli değişkenler altında nasıl sonuçlar ürettiği takip edilmesi gereken bir konudur. Bu nedenle ilgili meta-analiz çalışmalarının sürdürülmesi sağlam bir sentez alanyazını oluşturulması için önemli görünmektedir. 


\section{KAYNAKLAR}

*Allen, K.D., Wallace, D.P., Renes, D., Bowen, S.L., \& Burke, R.V. (2010). Use of video modeling to teach vocational skills to adolescents and young adults with autism spectrum disorders. Education and Treatment of Children, 33 (3), 339-349.

Ayres, K. M. \& Langone, J. (2005). Intervention and instruction with video for students with autism: A review of the literature. Education and Training in Developmental Disabilities, 40, 183-196.

*Banda, D.R., Copple, K.S., Koul, R.K., Sancibrin, S.L., \& Bogschutz, R.J. (2010). Video modeling interventions to teach spontaneous requesting using AAC devices to individuals with autism: A preliminary investigation. Disability and Rehabilitation, 32(16), 1364-1372.

Bandura, A. (1977). Social learning theory. Englewood Cliffs, NJ: Prentice Hall.

*Bellini, S., Akullian, J., \& Hopf, A. (2007). Increasing social engagement in young children with autism spectrum disorders using self-modeling. School Psychology, 36(5), 80-90.

Bellini, S., \& Akullian, J. (2007). A meta-analysis of video modeling and video self-modeling interventions for children and adolescents with autism spectrum disorders. Exceptional Children, 73, 261-284.

*Blum-Dimaya, A., Reeve, S.A., Reeve, K.F., \& Hoch, H. (2010). Teaching children with autism to play a video game using activity schedules and game-embedded simultaneous video modeling. Education and Treatment of Children, 33(3), 351-370.

*Boudreau, E., \& D'Entremont, B. (2010). Improving the pretend play skills of preschoolers with autism spectrum disorders: The effects of video modeling. Journal of Developmental and Physical Disabilities, 22, 415-431.

*Buggey, T., Hoomes, G., Sherberger, M.E., \& Williams, S. (2009). Facilitatinf social initiations of preschoolers with autism spectrum disorders using video self-modeling. Focus on Autism and Other Developmental Disabilities, 20(10), 1-12.

*Charlop, M., H., Dennis, B., McKenna, C., Carpenter, M.H., \& Greenberg, A.L. (2010). Teaching sociall expressive behaviors to children with autism through video modeling. Education and Treatment of Children, 33(3), 371-393.

*Cihak, D., Fahrenkrog, C., Ayres, M., K., \& Smith, C. (2010). The use of video modeling via a video Ipod and a system of east prompts to improve transitional behaviors for students with autism spectrum disorders in the general education classroom. Journal of Positive Behavior Intervention, 12(2), 103-115.

*Deitchman, C., Reeve, S.A., Reeve, K.F., \& Progar, P.R. (2010). Incorporating video feedback into selfmanagement training to promote generalization of social initiations by children with autism. Education and Treatment of Children, 33(3), 475-488.

Forness, S. R. (2001). Special education and related services: What we have learned from meta-analysis. Exceptionality, 9, 185-197.

*Hine, J. F. \& Wolery, M. (2006). Using point-of-view modeling to teach play to preschoolers with autism. Topics in Early Childhood Special Education, 26, 83 - 93.

Horner, R. H., Carr, E. G., Halle, J., McGee, G., Odom, A., \& Wolery, M. (2005). The use of single-subject research to identify evidence-based practice in special education. Council for Exceptional Children, 2, 165179. 
Kavale, K. A. (1984). Potential advantages of the meta-analysis technique for research inspecial education. The Journal of Special Education, 18, 61-72.

Kavale, K.A. (2001). Decision-making in special education: The function of metaanalysis.Exceptionality, 9, $245-$ 268.

*Keen, D., Brannigan, K. L., \& Cuskelly, M. (2007). Toilet training for children with autism: The effects of video modeling category. Journal of Developmental and Physical Disabilities, 19, 291-303.

*Kleeberger, V., \& Mirenda, P. (2010). Teaching generalized imitation skills to a preschooler with autism using video modeling. Journal of Positive Behavior Intervention, 12(2), 116-127.

Lloyd, L.L. (2001, March). Evidence-based practice. Why and what with an emphasis on research issues. Paper presented at the Early Childhood intervention Research Seminar, University of Pretoria, South Africa.

*MacDonald, R., Sacramone, S., Mansfield, R., Wiltz, K., \& Ahearn, W.H. (2009). Using video modeling to teach reciprocal pretend play to children with autism. Journal of Applied Behavior Analysis, 42, 43-55.

*Maione, L., \& Mirenda, P. (2006). Eff ects of video modeling and video feedback on peer-directed social language skills of a child with autism. Journal of Positive Behavior Interventions, 8, 106-118.

*Mechling, L.C., Gast, D. L., \& Cronin,B.A. (2006). The effects of presenting high-preference item, paired with choice, via computer-based video programming on task completion of students with autism. Focus on Autism and Other Developmental Disabilities, 21(1), 7-13.

*Murzynski, N. T., \& Bourret, J. C. (2007). Combining video modeling and least-to-most prompting for establishing response chains. Behavioral Interventions, 22, $147-152$. Nelson, J. R., \& Epstein, M.H. (2002). Report on evidence-based interventions: Recommended next steps. School Psychology Quarterly, 17, 493-499.

*Nikopoulos, C.K., Canavan, C., \& Nikopoulou-Smyrni, P. (2009). Generalized effects of video modeling establishing instructional stimulus control in children with autism. Journal of Positive Behavior Interventions, 11(4), 198-207.

*Palechka, G., \& MacDonald, R. (2010). A comparison of the acquisition of play skills using instructor-created video models and commercially available videos. Education and Treatment of Children, 33(3), 457-474.

Odom, S. L., Brantlinger, E., Gersten, R., Horner, R. H., Thompson, B., \& Harris, K., R. (2005). Research in special education: Scientific methods and evidence-based practices. Exceptional Children, 71, 137-149.

Odom, S.L., Collet-Klingenberg, L., Rogers, S. J., \& Hatton, D.D. (2010). Evidence-based practices in interventions for children nd youth with autism spectrum disorders. Preventing School Failure, 54(4), 275 282.

*Paterson, R. C., \& Arco, L. (2007). Using video modeling for generalizing toy play in children with autism. Behavior Modification, 31(5), 660-681.

*Rosenberg, N.E., Schwartz, I.S., \& Davis, C.A. (2010). Evaluating the utility of commercial videotapes for teaching hand washing to children with autism. Education and Treatment of Children, 33(3), 443-455.

*Sancho, K., Sidener, T.M., Reeve, S.A., \& Sidener, D.W. (2010). Two variations of video modeling interventions for teaching play skills to children with autism. Education and Treatment of Children, 33(3), 421-442. 
*Sansosti, F. J., \& Powell-Smith, A. K. (2008). Using computer presented social stories and video models to increase the social communication skills of children with high functioning autism spectrum disorders. Journal of Positive Behavior Interventions, 10(3), 162-178.

*Scattone, D. (2008). Enhancing the conversation skills of a boy with asperger's disorder through social stories and video modeling. Autism Developmental Disorder, 38, 395-400.

Schlosser, R.W. (2003). The ethicacy of augmentative and alternative communication toward evidence based practice, Sons Diego, CA: Academic Press.

Scruggs, T. E., \& Mastropieri, M. A. (1998). Summarizing single-subject research: Issues and applications. Behavior Modification, 22, 221-242.

Scruggs, T. E., Mastropieri, M. A., \& Casto, G. (1987). The quantitative synthesis of single subject research: Methodology and validation. Remedial and Special Education, 8(2), 24-33.

Stoiber, K.C (2002). Revisiting efforts on constructing a knowledge base of evidencebased intervention within school psychology. School Psychology Quarterly, 17, 533-546.

Tetreault, A.S., \& Lerman, D.C. (2010). Teaching social skills to children with autism using point-of-view video modeling. Education and Treatment of Children, 33(3), 395-419.

Waas. G. A. (2002). Identifying evidence-based interventions in school psychology: Building a bridge pr jousting with windmills? School Psychology Quarterly. 17, 508-517.

*işareti üst-analiz ve niteliksel özette yer alan makaleleri belirtmek için kullanılmıştır. 


\title{
Examining Video-Modeling in Teaching of Individuals with Autism: A Review and Meta-Analysis Sample
}

\author{
Necdet Karasu * \\ Gazi University
}

While autism spectrum disorder causes social, communicational, behavioral, and educational effects on individuals, and can also have detrimental effects on other family members', educators' and professionals' work and life. In order to benefit from the educational programs for students with autism at most, evidence based practices must be applied properly to reduce the problems caused by autism. Qualitative and quantitative summaries might help in identification video modeling as evidence based practices.

\section{Evidence-based practices}

The idea of evidence based practices was nurtured in the field of medicine. It found strong ground in education for itself. Waas (2002) emphasized the importance of a study as if it provided an answer for the effectiveness question. Lloyd (2001) defined evidence based practices as use of experimental study results. Scholesser (2003) defined it as use of most recent and accurate information provided by educational and clinical studies. Odom, Brantlinger, Gersten, Horner, Thompson ve Harris (2005) applied the definition provided by Research and Training Center on Early Childhood Development which is "informed by research, in which the characteristics and consequences of environmental variables are empirically established and the relationship directly informs what a practitioner can do to produce the desired outcome".

Kavale (1984) identified two approaches to cumulate the literature as qualitative and quantitative summaries.

\section{Literature reviews and meta-analysis}

Review studies and meta-analysis studies have been conducted for a long time in special education. Kavale (1984) pointed out that reviewing studies qualitatively can be questionable. Since personal beliefs of the

\footnotetext{
Assist. Prof. Dr. Gazi University, Faculty of Education, Department of Special Education, Ankara, E-mail: necdetkarasu@gazi.edu.tr
} 
reviewers, or bias of the reviewers can cause subjectivity discussions. Also, reviews can only provide framework for the topic.

Quantitative studies; however, can provide objective approach to cumulating literature. Effect-size calculations create an unbiased approach to cumulating the results of experimental studies. There are several methods to calculate effect-sizes for single-subject design studies. One of the methods in calculating effect-sizes is percentage of non-overlapping.

\section{Percentage of Nonoverlapping Data (PND)}

Scruggs, Mastropieri, and Casto (1987) introduced PND for the first time. The researchers compared the observations of treatment phase to baseline. The number of the observations higher than the highest baseline observation scores in treatment phase divided by the total number of the observations and multiplied with 100 in order to calculate a percentage based difference. To interpret the results, the researchers suggested that the scores above $75 \%$ should be considered as effective, the results above $50 \%$ should be considered as questionable, and the scores below $25 \%$ should be considered as not effective.

\section{Video modeling}

Bandura (1977) pointed out that children can learn several skills by observing others. Video modeling is based on same principle. Desired behavior examples are shown to the target individual via video use (Bellini \& Akullian, 2007). The individual watch the example and repeat the model. Video self-modeling is also a similar approach. The only difference is use of individuals' own good examples on the targeted behavior.

\section{Purpose of the Study}

Ayres and Langone (2005) reviewed the studies based on video modeling published until 2005. Bellini and Akullian (2007) differently conducted meta-analysis by using PND on the published until 2005. This study focused on providing detailed review and PND based effect-sizes for the published articles about video modeling after 2005.

\section{Method}

\section{Article Search}

The search started with internet based search engine use. Also, a detailed and extensive search had been completed by using several databases such as EBSCOHost, ERIC, PsychInfo. The keywords as autism, autism spectrum disorder, rett sendrome, asperger sendrome, video modeling, video self-modeling, pervasive developmental disability etc. had beed used to spot the articles.

\section{Article Selection Criteria}

The selected studies must have meet certain criteria: being published after 2005, written in English or Turkish, published in a peer-reviewed journal, used at least one type of video-modeling method, and applied a model of single subject design methods. In the following step, the articles had been classified into categories based on variable types, participants, models etc.

\section{Findings}

The search was successful on spotting 24 peer-reviewed articles published in scholarly journals.

\section{PND Results}

The resultes showed that the highest percentage was $100 \%$ and the lowest one was $0 \%$. The mean percentage was calculated as 69 . 


\section{Dependent Variables}

The selected studies mainly focused on communication and social skills. Also, play skills, daily living skills, vocational skills, and transition skills have been targeted by the researchers. The majority of the studies reported improvement or change in dependent variable; however, detailed visual analysis caused controversial findings. Eight out of 24 studies presented questionable figures. Usually, the results showed that the trend between baseline and treatment phases did not change. Some studies provided evidence that the observations stated present a decreasing trend in the observations even thought increase was aimed. In some examples, the level did not even changed for some participants.

\section{Participant characteristics}

The studies involved 59 participants and 56 of them were diagnosed with autism. The youngest participant was 2 years old and the oldest one was 43 years old. The mode age of participants was 4 and 30 of the participants were age between 0-6. Twenty four of the participants were between age 7-18 and five were older than 19. The majority (47) of the participant was male and only 12 participants were female.

\section{Discussion}

Ayres and Langone (2005) summarized that video modeling based interventions in education of individual with autism are effective. Also, Bellini and Akullian (2007) study provided evidence that video modeling is an effective intervention to use. However, both studies provided a mean effect-size which is on a critical level. The results could be considered as questionable or effective. The reported results based on visual analysis also lead into controversial results. 
2011, 12(2) 